\title{
PDCA cycle reports: a quality tool to improve physician hand hygiene compliance
}

\author{
P Gonçalves*, JY Kawagoe, MFDS Cardoso, CV Silva, ADR Toniolo, HMF Castagna, CM dos Santos, FG de Menezes, \\ L Correa
}

From 3rd International Conference on Prevention and Infection Control (ICPIC 2015)

Geneva, Switzerland. 16-19 June 2015

\section{Introduction}

Physician hand hygiene $(\mathrm{HH})$ compliance is often found to be lower than that of nurses in the literature. In our institution $\mathrm{HH}$ compliance among physicians was about $40 \%$ despite many ongoing activities supported by WHO Multimodal HH Strategy to improve it. In 2013, a HH improvement PDCA (Plan-Do-Check-Act) category was created and the best works awarded at annual institutional Quality Exhibits.

\section{Objectives}

Describe a strategy aimed at $\mathrm{HH}$ physician compliance improvement using a quality tool in 2013 and 2014.

\section{Methods}

Descriptive study at a private institution with inpatient (650-beds) and six outpatient facilities, where voluntary and multidisciplinary groups developed HH improvement programs engaging patients and healthcare workers (HCWs) using a quality tool cycle - PDCA in 2013 and 2014. There were many strategies and metrics applied, including $\mathrm{HH}$ compliance, $\mathrm{HH}$ products consumption, $\mathrm{HH}$ knowledge and perceptions by HCWs and patients. For $\mathrm{HH}$ compliance there was a pre and post intervention measure.

\section{Results}

In 2013, there were 30 PDCA works from outpatient and inpatient units/facilities, but 13 aimed at physician HH compliance. There were 1159 and 1393 opportunities and mean $\mathrm{HH}$ compliance of $35.2 \%$ and $54.6 \%$ pre and post intervention, respectively. In 2014 there were fewer PDCA works (19) presented and 6 aimed at physician HH compliance: 729 and 534 opportunities and mean $\mathrm{HH}$ compliance of $38.8 \%$ and $59.4 \%$ pre and post intervention, respectively. Engaging patients, HCWs and specially physicians was the main strategy used. The mean institutional $\mathrm{HH}$ compliance among physicians was $47.3 \%$ and $45.9 \%$ in 2013 and 2014 respectively.

\section{Conclusion}

This strategy aimed at physician $\mathrm{HH}$ compliance improvement increased 55.1\% and 53\% in 2013 and 2014 respectively. Comparing $\mathrm{HH}$ compliance post intervention, the mean was higher in 2014, reaching 59.4\%. The involvement and commitment of the team members as well as the managers and the coordinators was fundamental for the strategy successful.

\section{Disclosure of interest}

None declared.

Published: 16 June 2015

\section{References}

1. Pittet D, Hugonnet S, Harbath S: Effectiveness of a hospital-wide programme to improve compliance with hand hygiene. Lancet 2000, 356:1307-1312.

2. World Health Organization: WHO Guidelines on Hand Hygiene in Health Care: a Summary. Geneva: WHO; 2009.

\section{doi:10.1186/2047-2994-4-S1-P280}

Cite this article as: Gonçalves et al:: PDCA cycle reports: a quality tool to improve physician hand hygiene compliance. Antimicrobial Resistance and Infection Control 2015 4(Suppl 1):P280.

\footnotetext{
Infection Prevention and Control Service, Hospital Israelita Albert Einstein,
} São Paulo, Brazil 